Policy Research Working Paper 2824

\title{
Trade Policy and Labor Services
}

\section{Final Status Options for the West Bank and Gaza}

\author{
Maurice Schiff
}

The World Bank

Development Research Group

Trade

April 2002 


\begin{abstract}
Schiff considers the policy options of the West Bank and Gaza with respect to trade and the export of labor services. He concludes that:

- Nondiscriminatory trade policy is unambiguously superior to a free trade agreement with Israel.

- The West Bank and Gaza should pursue a nondiscriminatory trade policy with all its neighbors, but only on the condition that the trade policy be open,

transparent, and enforced by a credible lock-in mechanism. Otherwise, a customs union with Israel may be preferable.

- The Palestinian Authority should establish a system of fee-based permits for Palestinians working in Israel.

- The Palestinian Authority should consider allowing Jordanians access to the West Bank and Gaza labor market.
\end{abstract}

This paper - a product of Trade, Development Research Group-is part of a larger effort in the group to analyze trade and regional integration policies in the Middle East. Copies of the paper are available free from the World Bank, $1818 \mathrm{H}$ Street NW, Washington, DC 20433. Please contact Paulina Flewitt, room MC3-333, telephone 202-473-2724, fax 202-5221159, email address pflewitt@worldbank.org. Policy Research Working Papers are also posted on the Web at http:// econ.worldbank.org. The author may be contacted at mschiff@worldbank.org. April 2002. (38 pages)

The Policy Research Working Paper Series disseminates the findings of work in progress to encourage the exchange of ideas about development issues. An objective of the series is to get the findings out quickly, even if the presentations are less than fully polished. The papers carry the names of the authors and should be cited accordingly. The findings, interpretations, and conclusions expressed in this paper are entirely those of the authors. They do not necessarily represent the view of the World Bank, its Executive Directors, or the countries they represent. 


\title{
Trade Policy and Labor Services: Final Status Options for the West Bank and Gaza
}

\author{
Maurice Schiff* \\ Development Research Group \\ World Bank
}

* Thanks are due to Sebastien Dessus for the information provided and the useful discussions during the writing of the paper, to Elizabeth Ruppert Bulmer for her advice and detailed suggestions, and to Claus Astrup for his comments. 



\section{Table of Contents}

1. Introduction 3

2. Israel's Trade Regime 7

2.1. West Bank and Gaza $\quad 8$

3. Customs Union (CU) with Israel 9

3.1. Losses 9

3.1.1. Tariff and Purchase Tax 9

3.1.2. Value Added Tax (VAT) 10

3.1.3. Transfers 11

3.1.3.1. Smuggling 13

3.1.4. Sum of Losses 13

3.1.5. Transactions Costs 14

3.1.6. Standards 15

3.2. Benefits 15

3.2.1. Customs Administration $\quad 16$

3.2.2. Political Economy 16

3.3. Conclusion on $\mathrm{CU} \quad 18$

4. Free Trade Agreement (FTA) with Israel 20

4.1. Benefits 20

4.2. Rules of Origin 21

4.3. FTA with Jordan 24

4.4. FTA with Israel versus CU 24

4.5. Conclusion on NDTP, FTA or CU 25

5. Exports of Labor Services 25

5.1. Benefits 25

5.2. Losses 26

5.3. Palestinian Permit 28

5.4. Jordanian Labor 31

5.5. Conclusion on Labor Services $\quad 32$

6. Currency 33

7. Concluding Comments 34

References

$\begin{array}{ll}\text { Table } 1 & 37\end{array}$

$\begin{array}{ll}\text { Appendix } & 38\end{array}$ 



\section{Trade Policy and Labor Services: \\ Final Status Options for the West Bank and Gaza}

\section{Introduction}

Until 1993, Israel exercised full authority over the West Bank and Gaza (WBG), including over the WBG trade policy. In 1993, the Israeli government and the Palestinian Authority (PA) signed the Declaration of Principles (known as the Oslo accord). This provided the PA with authority over parts of WBG and required the establishment of economic relations between Israel and the PA. The 1994 Protocol on Economic Relations (referred to as the Paris Protocol) laid out transitional economic arrangements for the period until the final status stage between Israel and the Palestinians. This paper examines what economic arrangements would best serve WBG once that stage is reached. The focus is on trade policy, both with Israel and with the rest of the world, and on exports of labor services.

The WBG policy options are constrained by the fact that it is highly integrated with the Israeli economy, both through trade and through the labor market. WBG imports a total of $\$ 3.2$ billion, $\$ 2.4$ billion or $75 \%$ of which is imported from Israel (all figures are for 1998). ${ }^{l}$ WBG exports a total of about $\$ 730$ million, with close to $\$ 700$ million or $96 \%$ exported to Israel. WBG has a GDP of $\$ 4.25$ billion (about $5 \%$ of that of Israel) and a GNP of about $\$ 5$ billion. The difference between the two is due to the fact that some $20 \%$ of the Palestinian labor force typically works in Israel (before the recent intifada). Income per capita is higher in the West Bank than in Gaza, and is about $\$ 1,700$ for WBG as a whole, or about $10 \%$ of that of Israel.

The various policy options to be considered by WBG have economic implications as well as implications with respect to sovereignty and political control. As far as trade policies with Israel are concerned, a customs union $(\mathrm{CU})$ provides less political control for WBG than a free trade agreement (FTA), and an FTA provides less political control

\footnotetext{
${ }^{1} 1998$ is the most recent year with a more complete set of trade and other figures for WBG. Not all imports from Israel are Israeli products, as discussed later.
} 
than a non-discriminatory trade policy (NDTP). ${ }^{2}$ A NDTP treats Israel the same as any country with which WBG has no preferential agreement (thus charging Israel the MFN tariff). ${ }^{3}$ In addition to trade policy, policy options examined include those related to the export of labor services to Israel, as well as a brief section on currency.

An early study on WBG by Fischer et al. (1994) examined labor, fiscal, monetary, financial and foreign aid aspects, and provided a set of sensible policy recommendations. In trade, it recommends integration of Israel, WBG and Jordan, with an FTA in goods, services, capital and technology. The recommendation is based on the view that free trade provides the best opportunities for growth in the region.

Though this advice may seem to make eminent sense, it should be recalled that FTAs as well as other types of regional agreements are "second-best"-type policies, and assessing the welfare impact of moving from one second best (the existing $\mathrm{CU}$ ) to another one (the recommended FTA) is never simple. First, an FTA between Israel, WBG and Jordan is not the same as free trade since trade under an FTA is not free with excluded regions. Second, implementation of an FTA entails a number of complexities that require careful examination. This paper examines various policy options regarding trade and exports of labor services, and examines the costs and benefits of each.

The WBG currently has a (modified) customs union (CU) with Israel. This paper examines various trade policy options whose costs and benefits are summarized in Table 1. The alternative trade policy options for WBG that are considered are:

i) the continuation of the $\mathrm{CU}$, with or without improved sharing of revenues from tariffs and other trade taxes;

ii) a free trade agreement (FTA) with Israel;

iii) a non-discriminatory trade policy (NDTP); and

\footnotetext{
${ }^{2}$ A FTA frees trade between the member countries of the FTA while each maintains its own trade policy with respect to excluded countries. A CU also frees trade between member countries but constrains them to a common external trade policy. The latter typically entails detailed negotiations between them and implies a greater loss of sovereignty than a FTA. NDTP implies that a country determines its trade policy unilaterally and provides no preferential access to anyone.
} 
iv) an FTA between WBG and Jordan.

Table 1 summarizes the costs and benefits of the various trade policy options.

The paper concludes that the trade regime of conditional non-discrimination ("conditional NDTP") is likely to provide the greatest economic benefits to the WBG. Thus, the scheme that is viewed as economically most beneficial also provides WBG with the greatest degree of political control. The policy is referred to as a "conditional NDTP" because its choice is conditional on liberalizing the trade regime of WBG and applying a number of restrictions in order to prevent any backsliding of its trade policy, including binding tariffs at applied levels at the WTO and implementing credible mechanisms to prevent the use of anti-dumping and other restrictive non-tariff measures.

The NDTP option is unlikely to be optimal if these conditions are not met. In that case, because of the discipline it provides, a CU with Israel may be preferable, assuming trade and other taxes are shared more equitably. Finally, whatever the trade policy arrangement with Israel, the paper recommends that the Palestinian Authority (PA) establish a system of fee-based permits that Palestinian labor must obtain in order to work in Israel, and that it consider allowing access by Jordanian workers to the WBG labor market.

Costs and benefits of the various policies have been estimated. The estimates are only approximations because some of the underlying figures are not known with any great degree of precision and some of the costs and benefits cannot be estimated at all. However, none of the paper's conclusions depend on the precision of these estimates, which should be seen as providing some orders of magnitude and some clarity to the analysis.

The paper also assumes that the issue of high transactions costs associated with security checks and border closure will have been resolved in the final status stage. This assumption seems plausible for a situation where peace has been established, is accepted

\footnotetext{
${ }^{3}$ The MFN or most-favored-nation principle, the basic principle underlying the GATT and the WTO, states that a country will treat all countries equally from the viewpoint of access to its markets, i.e., it will not
} 
by both populations and trust prevails. However, even after a formal peace agreement has been signed, reaching such a situation may take time, and until then transactions costs associated with security may be important. In the case of the former Yugoslavia, Kaminski and de la Rocha (2001) show that trade among its constituent republics has so far not returned to its pre-war level, though this may also be due to the war-related destruction of productive resources. In any case, though security aspects are important, their effect is impossible to predict with any degree of precision (except to say that lack of security will have important costs for both Israel and WBG). However, one can say something about how changes in transactions costs affect the choice between the various trade policy options. This is done in Section 3.1 .5 below.

Panagariya and Diwan (1997) and others have also recommended, as part of a new trade policy for WBG, that Gaza be converted into a free port (Hong Kong-style). This paper would only stress that its success will hinge critically on a host of related policies. The establishment of a free port requires important investments, including a world-class port, warehousing facilities, communications and other infrastructure, the acquisition of specific skills, and more. The free port also requires simple and transparent rules and regulations, efficient public administration and streamlined public services. If such a policy is put into place, WBG is likely to benefit. On the other hand, if transactions costs remain high due to cumbersome, non-transparent rules and widespread rent-seeking activities, WBG will end up with large sunk costs and little return to show for it.

This assessment seems confirmed by Rao (2000). He examined forty three free zones in the Middle East. The sample included commercial, export processing, industrial and mixed zones, both public or private. Rao provides detailed reasons for the generally poor performance of these zones. The major reason identified is the uncompetitive and restrictive policy frameworks within which these zones operate. On the other hand, if the policy framework were such that a free zone in Gaza turned out to be a success, its expansion to the West Bank might have to be considered.

provide preferential access to any country. 


\section{Israel's Trade Regime}

This section draws in part on the 1999 WTO Trade Policy Review for Israel. Between 1993 and 1999, the simple average of MFN tariffs fell from 8.3\% to $7.5 \%$ (excluding ad valorem equivalents or AVEs). They fell in manufacturing from $8.5 \%$ to $7 \%$, but rose in agriculture from $5 \%$ to $20.6 \%$. The range of MFN tariff rates increased from $0-100 \%$ to $0-250 \%$ (from $0-40 \%$ to $0-250 \%$ in agriculture, and from $0-66 \%$ to 0 $215 \%$ in manufacturing). The standard deviation of the 1999 MFN tariff (whose simple average inclusive of AVEs was 8.7\%) was $15.5 \%$, reflecting a high degree of dispersion (the coefficient of variation is 1.8).

New FTA partners since 1993 include Canada, the Czech Republic, Hungary, Jordan, Poland, the Slovak Republic, Slovenia and Turkey. This is in addition to FTAs with the US, the EU and EFTA. These countries have duty-free access, mainly on industrial products. The recent FTAs go beyond trade preferences and contain provisions on trade-related aspects such as competition, state aid, intellectual property rights, safeguards, government procurement, and dispute settlement. As a result of the increasing number of FTAs, the actual average customs duties paid halved between 1993 and 1999, to a level of $1 \%$, with $75 \%$ of Israeli manufacturing imports entering under preferential (mostly duty-free) rates by 1998 . The increase in the MFN tariff rates on imports of agricultural products is mainly due to "tariffication," whereby non-tariff measures (such as quantitative restrictions) are replaced by equivalent tariffs, typically a first step in the process towards a more liberal trade regime. Food, beverage, clothing and footwear get higher protection.

Most imports and domestic products are subject to purchase taxes and the VAT, with some (e.g., tobacco and alcohol) subject to additional taxes. The purchase tax averages about $10 \%$ of the value of imports, or 10 times the average tariff rate. The VAT is $17 \%$.

Israel also took additional steps to liberalize its trade regime. First, the coverage of an additional tariff called the "safeguard levy" fell from $2.7 \%$ of tariff lines in 1992 to $0.8 \%$ in 1999. Second, as a result of the Uruguay Round Agreement and the more recent 
International Technology Agreement, Israel bound its rates on just over half its tariff lines by $1999 .{ }^{4}$ Third, Israel has not been an active user of its anti-dumping legislation. No coutervailing or safeguard measures were taken between 1993 and 1999. ${ }^{5}$ Fourth, Israel has also improved customs valuation and has abolished the "harama" system which increased the value of imports by 2 to $10 \%$ before tariffs were imposed. ${ }^{6}$

With respect to non-tariff measures (NTMs), $8.5 \%$ of tariff lines were subject to import licenses in 1999, and 39\% of tariff lines were subject to standards. For agriculture, the ratios were $23.5 \%$ and $85.8 \%$, respectively, while for manufacturing, they were $7.7 \%$ and $37.1 \%$. Thus, agriculture has been the more protected sector, both in terms of tariffs and in terms of NTMs.?

\subsection{West Bank and Gaza}

By virtue of belonging to a $\mathrm{CU}$, tariffs and purchase taxes on individual tariff lines are the same for Israel and $\mathrm{WBG}^{8}{ }^{8}$ This does not necessarily imply that average protection rates are the same because the composition of imports can differ, with one of the two having imports that are more skewed towards high-protection goods. This can be due to a different composition of goods, of source countries, or both.

\footnotetext{
${ }^{4}$ However, these were often above the applied MFN rates, which maintains an element of uncertainty for investors and importers. This could be reduced by binding at applied rates and by increasing the tariff line coverage.

${ }^{5}$ These measures allow for a temporary increase in the degree of protection.

${ }^{6}$ On the other hand, seasonal tariffs, and both MFN and preferential tariff quotas (tariff quotas provide concessional rates on imports up to a given quantity or quota), have been introduced in recent years and have reduced the transparency of the trade regime, as have a wide range of end-use provisions (granting tariff reduction for specified end-users). For some MFN tariff quotas, the concessional rate is higher than the applied rate and is redundant.

${ }^{7}$ Mandatory standards are increasingly being aligned with international standards. Standards and customs valuation were amended as part of obligations Israel took under the Uruguay round. In 1999, about $25 \%$ of the mandatory standards were equivalent to the international ones. Israel has also made extensive commitments under the GATT, especially in the financial services area, providing legal security for market access. It is also a party to the 1997 Agreement on Telecommunications Services (Fourth Protocol), the 1997 Information Technology Agreement (ITA), and the 1997 Agreement on Financial Services (Fifth Protocol), the WTO Trade-Related Aspects of Intellectual Property Rights (TRIPS) and the WTO Government Procurement Agreement (GPA).

"In fact, the arrangement between Israel and the WBG is known as a "modified CU" because WBG has access to a limited range of imports from Arab League member countries (goods on lists A1, A2 and B), whose value in 1998 was $\$ 35$ million or $1.1 \%$ of total WBG imports.
} 
For instance, the sum of the average MFN tariff rate and the purchase tax for Israel is about $11 \%$ (WTO, 2000), while it is about $16.6 \%$ for WBG or about $50 \%$ higher (Astrup and Dessus, 2000). As is shown in Section 3, the higher barriers in WBG associated with the different composition of imports makes the change from the $\mathrm{CU}$ to a non-discriminatory trade policy (NDTP) more attractive to WBG.

\section{Customs Union with Israel}

This section examines the pros and cons of maintaining a customs union (CU) arrangement with Israel. It also examines ways to make the $\mathrm{CU}$ more beneficial for WBG. The NDTP is used as the counterfactual relative to which the gains and losses of the CU are measured. I assume that under the NDTP the same MFN tariff rates are applied as under the $\mathrm{CU}$, and later examine the possibility of trade liberalization under the NDTP (Section 3.2.2).

\subsection{Losses}

There are three sources of economic losses for WBG in a CU arrangement with Israel. The first one consists of a loss of revenue from border taxes and the VAT associated with "indirect imports", the second consists of a net transfer due to both the trade deficit with Israel and differences in average border taxes, and the third-which is harder to quantify-relates to standards. These costs are first calculated relative to a counterfactual scenario of a NDTP by WBG vis-à-vis Israel with WBG having the same trade policy as Israel vis-à-vis the rest of the world (ROW), and then relative to a NDTP with unilateral trade liberalization by WBG.

\subsubsection{Tariff and Purchase Tax}

Israel charges both a tariff and a purchase tax on imports from ROW, including on imports that are destined for WBG. The WBG imports from the ROW that transit through Israel enter in one of two ways. They either enter as "direct imports" to WBG, with the WBG destination of the goods clearly identified, or as "indirect imports" whose destination is declared as being Israel, and where the goods are later exported to WBG. The latter are typically imported by an Israeli firm, and then either re-exported to WBG 
(possibly without the knowledge of the original importer) or purchased by Palestinians (such as those working in Israel) and taken back to WBG.

The tariff and purchase tax revenues on direct imports to WBG are transferred by Israel to the PA (less a 3\% service charge) through a clearance system. This is not the case for indirect imports. Imports of WBG are about $\$ 3.2$ billion (1998 figures). Direct imports from the ROW were close to $\$ 800$ million ( $\$ 423$ million from FTA countries, $\$ 35$ million from Arab League members, and $\$ 312$ million from others). Imports from Israel in 1998 amounted to the rest, or $\$ 2.4$ billion. These imports include both Israeli products and indirect imports. The level of indirect imports is not known with any degree of precision. It is assumed here that they amounted to $\$ 800$ million (equal to direct imports). ${ }^{9}$ This implies that imports of Israeli products amounted to $\$ 1.6$ billion, or half the total of imports by WBG.

WBG captures neither the import tax revenues nor the purchase tax revenues on indirect imports (though these taxes are included in the price that WBG pays for its indirect imports). The average rate of import tariff plus purchase tax on imports by WBG is $16.6 \%$. Thus, the loss of tax revenue (and welfare) on indirect imports from the ROW equals $\$ 133$ million ( $16.6 \%$ of $\$ 800$ million) or $3.2 \%$ of GDP. This estimate is somewhat lower than that provided in EC (1999) where the loss of tax revenue from indirect imports is estimated at 4\% of GDP for 1996 and 1997, which would amount to $\$ 160$ million in $1998 .^{10}$

\subsubsection{Value Added Tax (VAT)}

Israel also charges a VAT of $17 \%$ on imports and domestic sales. For direct imports, revenues from the VAT are transferred to the Palestinian Authority (PA). WBG importers of products from Israel (either produced in Israel or indirect imports) who pay the Israeli VAT can apply for reimbursement, and if so, the VAT should not affect the

\footnotetext{
${ }^{9}$ This figure is a "guesstimate" provided in conversations with World Bank economists working on WBG.

${ }^{10}$ This result would be obtained in this paper if it were assumed that indirect imports amounted to $\$ 960$ million and direct imports amounted to $\$ 640$ million, or $60 \%$ and $40 \%$, respectively, of total foreign imports.
} 
price of Israeli products sold in WBG. However, it is likely that some leakage will take place and not all such transactions will be reported, either because the transactions costs involved are higher than the expected refund or in order to avoid paying the VAT. Estimating the importance of this phenomenon is likely to be difficult. This type of leakage is also likely to take place under a NDTP, though probably to a smaller extent because a NDTP entails border controls. Assuming that the degree of leakage under the CU is $10 \%$ larger than under a NDTP ( $10 \%$ of $\$ 2.4$ billion or $\$ 240$ million), the loss of revenue (and welfare) for WBG would amount to $17 \%$ of $\$ 240$ million or $\$ 41$ million. Consequently, the loss for WBG associated with the CU with Israel amounts to $\$ 174$ million so far.

\subsubsection{Transfers}

The WBG exports about $\$ 700$ million per year to Israel and imports $\$ 1.6$ billion of products produced in Israel, with a $\$ 900$ million trade deficit. WBG experiences negative transfers on its trade in Israeli and WBG products, both because of its trade deficit and because of its higher protection. The reason is as follows. WBG protects its domestic output through trade taxes amounting to $16.6 \%$ on imports from the ROW. With the CU, Israel exports its own output to WBG at zero tariff, and this implies a loss of tax revenue for WBG. ${ }^{11}$ On the other hand, given Israel's average protection of $11 \%$, WBG exports to Israel at a higher price because it does not pay the $11 \%$ trade taxes. This is a gain for WBG. ${ }^{12}$

Note that the $16.6 \%$ import tax applied at the WBG border with Israel under a NDTP would not raise prices in WBG if homogeneity between Israeli, WBG and ROW goods and services is assumed (see below). This is because the change from the CU to a NDTP does not change the level of border taxes but simply changes the location where the border tax is collected, from Israel's border with the ROW to the border between Israel and WBG.

\footnotetext{
"The welfare gain for Israel of not paying these taxes is smaller than the loss for WBG because of the inefficiency due to the trade diversion associated with the CU (some of Israel's exports to WBG are produced at a higher cost than the cost of importing from the rest of the world).

${ }^{12}$ This benefit for WBG is somewhat smaller than the revenue loss for Israel. This is because part of the WBG exports are produced at a higher cost than the cost of importing the same goods from the rest of the world (i.e., they entail trade diversion).
} 
For two reasons (at least), these transfers are not simply obtained by multiplying the level of protection by the value of imports or exports. First, part of that trade may be in non-tradable goods and services, and prices of non-tradables are not directly affected by protection. ${ }^{13}$ Second, domestically produced goods and those imported from the partner and from the ROW may not be perfect substitutes, even within the same tariff line. Under the assumption of heterogeneity, these goods are imperfect substitutes and their domestic price does not change by the full amount of the protection. Under the assumption of homogeneity, prices do change by the full amount of the protection in small open economies (including Israel and WBG).

Starting with services, exports to WBG of services produced by Israel amounted to some $\$ 492$ million (out of a total of $\$ 1.6$ billion). The share of non-tradable services in these exports amounted to about $80 \%$ or $\$ 394$ million (see Appendix for calculations). Thus, total exports of Israeli goods and services to WBG that are internationally tradable equal $\$ 1.206$ billion ( $\$ 1.6$ billion - $\$ 394$ million). On the other hand, WBG exports $\$ 51$ million of services to Israel. Assuming the same degree of non-tradability (of $80 \%$ ), some $\$ 40$ million are not tradable. Moreover, WBG exports stones to Israel. These are not traded internationally and amount to $11.3 \%$ of total WBG exports to Israel, or about $\$ 80$ million. Thus, total WBG exports to Israel of internationally tradable goods and services is $\$ 580$ million ( $\$ 700$ million - $\$ 120$ million).

Given these figures, and assuming first homogeneity (perfect substitutability between domestically produced goods and imports), WBG loses on its imports of Israeli goods and services a total of $\$ 200$ million under the CU (16.6\% of $\$ 1.206$ billion). This is because Israel can sell at the higher price in WBG due to WBG's tariffs with the ROW, but WBG does not collect any tariff revenue on these imports. On the other hand, it gains $\$ 64$ million (11\% of $\$ 580$ million). Thus, the net loss is $\$ 136$ million.

${ }^{13}$ Even if prices of non-tradable goods and services are indirectly affected by protection, as long as there are no distortions in the non-tradable markets, changes in their prices or output has no welfare implications. 
Under heterogeneity, the net loss may be smaller. To compute that loss requires a general equilibrium framework as well as knowledge of--or assumptions about-elasticities of substitution in production and consumption of domestic and imported products, and this is beyond the scope of this paper. Such a framework was used by Astrup and Dessus (2000) to examine the impact of policy changes on WBG, and their results fall within the range of results found in this paper. Consequently, the loss for WBG associated with the CU with Israel is ( $\$ 174$ million $+\$ 136$ million $\Rightarrow$ ) $\$ 310$ million.

\subsubsection{Smuggling}

The above assumes that the PA is able to control the border effectively and collect all border taxes. The reality, however, is that the border is extremely porous, particularly between the West Bank and Israel. Then, WBG is only likely to collect part of the border taxes, even under a NDTP. A leakage of $20 \%$ may seem reasonable, but a leakage of $40 \%$ is assumed here to show that a NDTP is preferable to the CU even under assumptions that favor the CU. Thus, assuming that $40 \%$ of Israeli exports are smuggled and enter WBG undetected, the authorities only collect $60 \%$ of potential trade tax revenue, or $\$ 120$ million (60\% of the $\$ 200$ million obtained in the previous section). Some of the $\$ 80$ million of lost trade tax revenue will be wasted (in real resources spent to avoid detection) and the rest is likely to accrue to Palestinian traders and customs officials. Assuming that half the lost revenue is wasted and half accrues to Palestinian traders, the welfare loss for WBG associated with the CU amounts to $\$ 160$ million ( $\$ 120$ million of revenue plus $\$ 40$ million accruing to traders and customs officers). Given WBG's gains of $\$ 64$ million on exports to Israel, the net welfare loss for WBG is $\$ 96$ million. Thus, depending on the degree of leakage and the rents smugglers collect, the loss due to net negative transfers ranges between $\$ 96$ million and $\$ 136$ million.

\subsubsection{Sum of Losses}

The sum of the WBG losses (lost revenues from tariff, purchase tax and VAT, and negative transfers due to the trade deficit with Israel) ranges from $\$ 270$ million to $\$ 310$ million, or between $6.4 \%$ and $7.3 \%$ of the GDP of WBG. In present value (with a real discount rate of, say, $6 \%$ ), this loss amounts to between $\$ 4.5$ billion and $\$ 5.2$ billion, or between $106 \%$ and $122 \%$ of GDP. 
Total tax revenue losses under the CU amount to $\$ 334$ million in the presence of smuggling, or $6.9 \%$ of GDP, and amount to $\$ 374$ million in the absence of smuggling, or $8.8 \%$ of GDP. ${ }^{14}$ Thus, replacing the CU with a NDTP should enable the PA to significantly lower border or other taxes without loss of revenue, and this should result in additional welfare gains.

\subsubsection{Transactions Costs}

One issue not examined so far is the impact of transactions costs. What follows is not an analysis of the impact of a reduction in transactions costs per se (on that, see Astrup and Dessus, 2000). Rather, the analysis deals with how a reduction in transactions costs affects the comparison between the CU and a NDTP. Calculations are presented under the assumption that smuggling does not take place. Conclusions are the same under the assumption of smuggling. If transactions costs were reduced in the final status stage, trade between Israel and WBG would be larger. The non-intifada transactions costs on exports from WBG to Israel have been estimated at 35\% (Astrup and Dessus, 2000). Those from Israel to WBG are smaller, and it is assumed here that they amount to $15 \%$.

Assume that in the final status stage, transactions costs are reduced to $5 \%$ for trade in both directions between Israel and WBG. This implies that the net price obtained by Israeli exporters would be $95 \%$ rather than $85 \%$ of the price in WBG, which amounts to an increase of $.118(=10 / 85)$ or $11.8 \%$. Assuming an elasticity of supply of Israeli exports to WBG equal to one, Israeli exports of internationally tradable goods to WBG under lower transactions costs would be $\$ 1.348$ billion rather than $\$ 1.206$ billion, and the WBG loss from the CU (of $16.6 \%$ ) would be equal to $\$ 224$ million rather than $\$ 200$ million (or an increase of $\$ 24$ million). The net price for Palestinian exporters would be equal to $95 \%$ rather than $65 \%$ of the export price, which amounts to a $46.2 \%$ increase. With the same supply elasticity for exports from WBG to Israel, WBG exports would be equal to $\$ 848$ million rather than $\$ 580$ million, and the gain (of $11 \%$ ) would amount to $\$ 93$ million rather than $\$ 64$ million (or $\$ 29$ million more).

\footnotetext{
${ }^{14}$ Total tax revenue losses are larger by $\$ 64$ million because the positive transfer of $\$ 64$ million (associated with the fact that WBG does not pay trade taxes on its exports to Israel) accrues to exporters and not to tax
} 
Thus, the net loss of the CU under lower transactions costs would be $\$ 131$ million rather than $\$ 136$ million, or a difference of less than $4 \%$. Assuming an elasticity of export supply of two rather than one results in a net welfare loss of the $\mathrm{CU}$ of $\$ 126$ million. And assuming that transactions costs for WBG fall only to $10 \%$ rather than to $5 \%$ raises the welfare loss from $\$ 136$ million to $\$ 140$ million with an elasticity of one, and to $\$ 144$ million with an elasticity of two. In other words, the reduction in transactions costs does not have a significant impact on the welfare comparison between the CU and a NDTP. The reason is that the reduction in transactions costs is larger for the WBG but the value of Israeli exports as well as the WBG border taxes are larger, and the two sets of effects approximately cancel each other out.

\subsubsection{Standards}

Israel imposes various standards on imports into the CU $339 \%$ of tariff lines were subject to standards). These are imposed partly for the public good (such as sanitary and phyto-sanitary standards in agriculture, and technical standards in industry) and partly as a protectionist device (and the two sets of standards typically overlap). Both may result in costs for WBG. The optimal level of the public-good standards is in part a function of the income of the society that imposes them. These standards are likely to be set at levels that are close to optimal for Israel but may be too high for WBG (whose per capita income is only $10 \%$ of that of Israel). Second, the protectionist standards are imposed to protect Israeli industry and not for the benefit of WBG. Under a NDTP, WBG would be able to impose standards that suit its needs. On the other hand, there is a risk that the PA might use standards as a tool for protection of some of its own inefficient sectors, thereby doing more harm than good. Consequently, one cannot determine a priori whether WBG standards will be better than Israeli ones.

\section{2. $\underline{\text { Benefits }}$}

There are two types of benefits from a CU, one associated with avoiding the cost of establishing and managing alternative trade arrangements with Israel, and the second dealing with issues of political economy.

or customs authorities. 


\subsubsection{Customs Administration}

With a CU, WBG avoids the costs associated with setting up customs borders (training personnel, building customs posts, buying computers), and collecting taxes to reflect differences in VAT, excise and tariff rates on third-party trade. The operating cost has been reported to amount to $1.5 \%$ of the value of imports (Daoud, 2000, p. 21). At $\$ 3.2$ billion of imports, this amounts to savings of $\$ 48$ million. Thus, the net loss of the CU so far is $\$ 262$ million ( $\$ 310$ million - $\$ 48$ million) or $6.1 \%$ of GDP in the absence of smuggling, and $\$ 222$ million ( $\$ 270$ million - $\$ 48$ million) or $5.2 \%$ of GDP in the presence of smuggling.

The $\$ 48$ million is the cost of subcontracting customs operations to a private firm. Daoud (2000, p. 21) estimates the cost of five commercial and five passenger stations to be about half the cost of the privatization solution. Whether the former will do the job, given the border's high degree of porosity, is an open question. Daoud argues that the private solution, though more expensive, will reduce leakages and the losses of revenue associated with customs personnel's lack of experience (and possible lack of rigor in enforcing customs regulations).

Another important cost that is being avoided with the $\mathrm{CU}$ is the lost income suffered by traders due to delays at the border. This cost can be minimized under a NDTP by lowering MFN tariffs, simplifying the tariff structure and making it more uniform. This would also reduce the discretionary power of customs authorities and would reduce the lobbying and corruption that complex tariff structures typically entail. This is examined in Section 3.2.2 below.

\subsubsection{Political Economy}

A CU with Israel takes trade policy mostly out of the hands of the PA. Though this entails a loss of sovereignty as compared with an FTA or a NDTP, it may generate economic benefits. This depends on three issues: i) the CU's trade policy, ii) the trade policy that would prevail in WBG in the absence of a $\mathrm{CU}$, and iii) the resources spent to generate such a trade policy. 
Israel's trade policy has been liberalized in recent years, with an average MFN tariff of $7 \%$ in 1999 and an overall average tariff of $1 \%$, and import licenses only on $8.5 \%$ of tariff lines. The CU's external trade policy could benefit from further liberalization, though it is quite liberal and has been liberalizing. Moreover, since WBG's net trade with Israel is weighted towards agricultural goods, it should benefit from the higher protection provided to agriculture (for a given average protection rate). And though it is possible that WBG might have a better trade policy under an alternative arrangement, this is by no means certain. This brings us to the second and third points.

The PA has the choice, under a NDTP with respect to Israel, either of implementing a better trade policy than that of the CU or not. An important question is whether the PA will be strong enough, and whether WBG will have sufficientlydeveloped supporting public institutions with the right kind of incentive structure, in order to make decisions for the long-term benefit of the entire population rather than for the short-term benefit of particular groups. Institutions in WBG are currently weak and transparency in public affairs is limited. And a number of centers of economic and political power are likely to continue exerting pressure on the government in order to obtain favors through the political system rather than through the market. All these make it seem doubtful that the political economy equilibrium will result in a liberal and transparent trade policy. Thus, the outcome under a NDTP may very well be a more restrictive and distorted trade policy than the one under a CU with Israel. ${ }^{15} 16$

Moreover, such a trade policy is likely to be the (equilibrium) outcome of the investment of real resources in the lobbying effort of different groups in order to obtain the type of protection that favors them. Thus, not only is there a danger that the trade policy itself will be harmful to the economy of WBG, but the process of reaching such a policy may also result in a significant waste of scarce resources.

\footnotetext{
${ }^{15}$ Any policy makers-whether the PA or others--face pressures from interest groups. The point, however, is that the PA is weak and its functioning is not transparent or subject to control by elected representatives, and policy outcomes will not necessarily satisfy the public good.

${ }^{16}$ Israel allows WBG to import limited quantities of certain goods from Arab countries that are on lists Al and A2. EC (1999) reports that monopolies have been created in WBG, partly in response to these quotas. Such an outcome is by no means inevitable as the quotas could be auctioned in a competitive environment.
} 
The discipline imposed on the trade policy of WBG that results from a CU with Israel may well be the major benefit of maintaining the present trade arrangement. Take for instance the case of Botswana, a member of the Southern African Customs Union (SACU), which has been the fastest growing country in Sub-Saharan Africa in recent years. Botswana's trade policy is determined by South Africa. And though South Africa's past protectionist trade policy was much worse than the one presently pursued by Israel, the arrangement led to rapid growth in Botswana by taking trade policy out of the hands of its government and interest groups, and allowing all energies to concentrate on using market activities rather than the political system to generate income.

\subsection{Conclusion on $\mathrm{CU}$}

The analysis has shown that a NDTP with the same structure of trade taxes as the $\mathrm{CU}$ is superior to the CU. Whether the PA has total control of its border or not, the loss from the CU relative to a NDTP is important. That loss would be significantly reduced if revenues from border taxes were shared more equitably under an alternative system (such as on a macroeconomic basis a la SACU).

In fact, welfare under a NDTP could be raised further by unilaterally lowering the level of trade taxes and rationalizing them. For a (very) small open economy such as WBG, lowering MFN tariffs would unambiguously improve efficiency and raise welfare. However, moving to a NDTP runs the risk that the trade regime resulting from political economy forces could be highly protectionist. ${ }^{17}$ Thus, a "conditional NDTP" where trade

policies are constrained to be liberal is likely to be superior to a CU, though a protectionist NDTP may well be worse.

If the present overall $\mathrm{CU}$ framework is maintained, it will require several changes. First, as was noted above, WBG experiences losses both in terms of tax revenue on imports from the ROW and from transfers due to its trade deficit with Israel. On tax revenue, one option is to improve the implementation of a notional border, with better 
labeling and other means of identifying the goods whose final destination is WBG. However, given the porosity of the border described earlier (including daily movement of Palestinian workers), a preferable option may be the sharing of import taxes on a macroeconomic basis. This is the system used by SACU. South Africa collects all border taxes and shares them with the other members of SACU (Botswana, Lesotho, Namibia and Swaziland). The share of border taxes given to South Africa's partners corresponds to each partner's share in SACU's GDP, multiplied by a coefficient larger than one in order to compensate them for the fact that SACU's trade policy corresponds to South Africa's priorities rather than to theirs.

Second, WBG experiences a real income loss due to its trade deficit with Israel (and higher average tariff). One solution is for Israel to reimburse WBG for an estimate of the losses. This type of arrangement has occurred in CUs where the distribution of gains and losses was deemed to be asymmetric and threatened the survival of the CU. In fact, CUs in Africa, Latin America and Asia collapsed in the past because a favored member refused to renegotiate the distribution of gains and losses. ${ }^{18}$ Another alternative would be for Israel to lower its purchase tax. This would also help with the loss associated with the tax revenue problem. ${ }^{19}$

\footnotetext{
${ }^{17}$ The evidence from other newly independent states is not very reassuring with respect to the quality of governance. This is true of most developing countries that became independent following de-colonization as well as for many of the republics of the former Soviet Union.

${ }^{18}$ For instance, this occurred in the 1960s with the EAC (East African Community) which fell apart because Tanzania and Uganda were dissatisfied with the transfers accruing to Kenya; and the same occurred in the 1960s when Honduras left the CACM (Central American Common Market) in reaction to El Salvador's refusal to renegotiate the distribution of tariff revenues. This problem was also a factor in the war in the 1970s between East Pakistan (now Bangladesh) and West Pakistan (now Pakistan), and in the US Civil War between the North and the South (World Bank, 2000).

${ }^{19}$ WBG uses the Israeli currency (NIS) for most of its transactions, though not as a reserve currency. If WBG had a CU with Israel that included a better distribution of revenues from trade taxes, its relationship to Israel would resemble the one that existed between Luxembourg and Belgium. These two countries were members of a monetary union with Belgium having a monopoly on monetary policy (still true until January 1, 2002), and they were members of a customs union (with the Netherlands). Another similarity is that Luxembourg is landlocked and part of its imports came through the ports of Antwerp and Rotterdam, so that the reimbursement of trade taxes was also an issue. The arrangement seems to have worked for Luxembourg. Of course, Luxembourg has the advantage of having large, rich and open neighbors, which, as Vamvakidis (1998) has shown, has a strong impact on a country's growth, and it has benefited from serving as a tax haven.
} 
One final issue is that if WBG remains in a CU with Israel, it is likely to have little or no say with respect to its evolution. This is of course unattractive from the viewpoint of political sovereignty. However, since Israel has pursued a process of liberalization in recent years and is likely to continue to do so, the economic implications of Israeli control of the trade policy of WBG need not be adverse. Kessler (Ch. 5, p. 45, in EC Report, 1999) argues that Israeli protection probably meets Palestinian needs relatively well, with most imports from EU, US and EFTA entering duty free, and low MFN tariffs on inputs, raw materials and investment goods, and higher tariffs and NTMs on consumer goods. On the other hand, it is less likely that Israel's standards are favorable to WBG. And the CU also imposes a cost on WBG by limiting its trade with members of the Arab League.

The CU option may entail an additional cost. Section 5.3 recommends that the PA require a fee-based permit to work in Israel. This can only be effective if the PA controls its border with Israel. Control of labor flows across the border will be harder under a CU than under a NDTP.

\section{Free Trade Agreement (FTA) with Israel}

The FTA option is first compared to a NDTP and then to the CU (Section 4.4). Under a FTA, WBG would establish border controls, and taxes on its imports from the ROW would be collected by the PA rather than by Israeli authorities.

\subsection{Benefits}

A NDTP was shown in Section 3 to be superior to the CU (assuming WBG's freedom under a NDTP to set its own trade policy does not result in closing the economy). A NDTP is also superior to an FTA for two reasons at least. First, the net negative transfer ranging between $\$ 96$ million and $\$ 136$ million under the $\mathrm{CU}$, and which is associated with WBG's trade deficit with Israel, remains under an FTA but not under a NTDP. Second, a NTDP does not require rules of origin (and neither does a CU), and these can be very costly for the authorities as well as for traders and for the economy as a whole. 


\subsection{Rules of Origin (ROO)}

Replacing the WBG-Israel CU with an FTA requires WBG to establish border controls. These controls entail a number of significant costs, including the establishment and operation of a customs administration. These costs are also incurred under a NDTP. However, one of the customs administration principal activities under an FTA is the control of the origin of goods exported by Israel to WBG. This is required in order to avoid the problem of "trade deflection." Under an FTA, WBG might have higher tariffs than Israel on a variety of products. These products could then be imported by Israeli firms, paying the lower Israeli tariff, and sold duty-free in the WBG. This is known as "trade deflection."

Trade deflection has the following consequences. First, WBG would lose control over its external trade policy. Products would not pay the higher WBG tariff but rather the lower Israeli tariff. Thus, the effective tariff on goods imported by WBG would be the lower Israeli tariff. But WBG would not even collect the revenue associated with that lower tariff because the firms importing the goods would be paying the lower tariff to the Israeli customs authorities. In other words, WBG would then be better off adopting the lower Israeli tariff because this would eliminate any incentive for trade deflection and WBG would at least collect the tariff revenue associated with the lower tariff.

In order to avoid the consequences of trade deflection, the WBG customs administration needs to control the origin of goods that it imports from Israel. Ideally, duty-free trade between WBG and Israel should apply to goods that are produced within the FTA bloc (WBG and Israel), and should not apply to goods imported from outside the FTA bloc. This may seem simple in theory, but the reality of controlling the origin of goods is complicated. Goods exported by Israel to WBG are likely to incorporate inputs imported from outside the FTA bloc. In that case, only the value added (VA) can be considered as having been produced inside the bloc. The question arises then as to whether these goods should be considered as having been produced inside the bloc or not. If they are, they enter WBG duty-free. If not, they must pay the tariff imposed by WBG. 
Ideally, an FTA should entail the free movement of value added produced inside the bloc. However, trade takes place in final goods and not in value added. Consequently, rules of origin ( $\mathrm{ROO}$ ) have been devised in order to (imperfectly) control for the origin of goods. The most common rule uses the share of value added as a criterion, in which case the parties agree that in order for a country to obtain preferential access to its partner's market for a given product, the value added produced inside the bloc must be above a certain percentage of the value of the product. ${ }^{20}$

The attempt to solve the problem of trade deflection through ROO results in a number of new problems. The paper focuses on five of them. ${ }^{21}$ First, ROO can lead to additional trade diversion and a welfare loss. For instance, assume that WBG can import inputs either from Israel or from the rest of the world (ROW), but that if it uses inputs from the ROW, it will not comply with the ROO and will not receive trade preferences on its exports to Israel (i.e., it will have to pay the tariff). The cost of the inputs from the ROW is 50 while the cost of the same inputs from Israel is 60 (say, because of $20 \%$ protection on them). Assume that the tariff Israel charges on imports of the final good from the ROW is 20. Then, it is advantageous for WBG to buy the expensive inputs in Israel because, even though the inputs cost 10 more, WBG avoids paying 20 on its exports to Israel. Thus, ROO generate additional trade diversion: the ROO has resulted in an inefficiency loss of 10 since WBG was forced to buy more expensive inputs in order to benefit from its duty-free access to Israel's market. Thus, ROO can result in misallocation of resources (in this case in Israel, which is producing inputs inefficiently) and a transfer (of 10) from WBG to Israel.

Second, for small countries such as WBG, complying with ROO is likely to be harder than for Israel. WBG is a much smaller economy, with an annual per capita income equal to $10 \%$ of that of Israel (about $\$ 1,700$ versus $\$ 17,000$ ) and a GNP equal to some $5 \%$ of that of Israel. WBG is thus significantly more dependent than Israel on

\footnotetext{
${ }^{20}$ Under other ROO, a good will be considered to be produced inside the bloc if i) it entails a substantial transformation of the inputs from outside the bloc, where the criterion typically is that the tariff line of the product differs from that of the inputs (say, steel versus automobiles), or ii) an essential component is produced inside the bloc (say, the motherboard for computers).

${ }^{21}$ Most of these problems are examined in Krueger (1997).
} 
imported inputs and components needed for production. It is therefore likely to be much harder for WBG than for Israel to comply with ROO requirements. This implies that for a number of products, either WBG will have to pay the Israeli MFN tariff on its exports to Israel or it will have to buy more expensive Israeli inputs.

Third, ROO are typically quite complex and enforcing them can be very costly for the authorities but even more so for exporters. The book that describes NAFTA's ROO is 200 pages long. Enforcing such complex rules entails a variety of additional costs, over and above the standard costs of customs administration in the case where MFN tariffs apply to all countries.

Proving origin (including obtaining all the necessary documents) can be very costly for exporters as well. These costs have been estimated by Herin (1986) at 3 to $5 \%$ of the f.o.b. price for EFTA countries. In WBG, a poorer region with less experience in customs administration, costs of border delays are likely to be larger than in EFTA countries. Given WBG's FTAs with Israel, the EU and the US, imports from FTA regions would amount to about $\$ 2.8$ billion. With compliance costs for exporters estimated at three to five percent of imports, the cost would be equal to $\$ 84$ to $\$ 140$ million. Astrup-Dessus (2001) estimate the loss due to ROO at $2.8 \%$ of welfare (i.e., of GDP of $\$ 4.25$ billion) or $\$ 140$ million. Including this cost reduces the net benefit of the FTA to something close to zero.

Fourth, ROO can be, and in fact always are, used as protectionist devices. This further restricts the free movement of goods between partners. Thus, producers in WBG might insist on restrictive ROO to prevent competition from cheaper Israeli imports. This is what occurred in NAFTA with textiles. In order to protect its textile industry from Mexican imports, the US insisted in the negotiations on the "triple transformation test." This ROO requires that the yarn, the cloth and the garments all have to be fully produced within NAFTA in order for Mexican exports to be conferred NAFTA origin and enter the US duty-free. Thus, Mexican producers must buy all their inputs from inside NAFTA, even if these are more expensive than inputs produced elsewhere, in order to obtain NAFTA preferences. And this is not the only case in NAFTA where ROO were used for 
protectionist purposes. Restrictive ROO will reduce the degree of competition in WBG and will reduce the duty-free access of WBG exports to Israel.

Fifth, Israel has an FTA with Jordan and WBG is also likely to consider having one in the final status stage. Moreover, WBG has FTAs with the US and the EU (and with Turkey because it has a CU with the EU), and may have more FTAs in the final status stage (following Israel's example which has FTAs with various Central and Eastern European countries). An independent trade policy implies establishing ROO for each and every one of the FTAs. This is likely to result in a "spaghetti bowl" (which originally referred to overlapping FTAs in Latin America). These overlapping FTAs are likely to greatly complicate the administration of ROO for WBG and to greatly increase their cost. An FTA with Israel will further complicate the management of ROO.

The various points enumerated above indicate that ROO can be very costly, especially for a small economy like WBG that needs foreign markets to grow. From that viewpoint alone, an FTA with Israel is less desirable than a NDTP. If one only includes the cost to exporters of establishing the origin of their goods, which range from $\$ 84$ million to $\$ 140$ million, and the negative transfers, which range from $\$ 96$ million to $\$ 136$ million, the benefit of a NDTP relative to an FTA ranges from $\$ 180$ million to $\$ 276$ million, or from $4.2 \%$ to $6.5 \%$ of GDP. And this does not include the other FTA costs associated with ROO (denoted by the letter " $x$ " in Table 1).

\subsection{FTA with Jordan}

What about an FTA between WBG and Jordan? Such an FTA will require rules of origin, and the costs associated with those are large, as examined in Section 4.2. Moreover, Jordan has been liberalizing its economy, so that WBG is unlikely to gain more from any preferential access to Jordan than it will lose from giving preferential access to Jordan in its own market.

\subsection{FTA with Israel versus CU}

The analysis so far has shown that a liberal NDTP is superior to the CU and to an FTA. What about the comparison between an FTA and the CU? Border taxes and the 
VAT on indirect imports will be collected under an FTA but not under the CU, amounting to a gain of $\$ 174$ million for the former. On the other hand, an FTA will require border controls and customs administration, whose operating cost (not including any setup cost) has been estimated at $\$ 48$ million. An FTA will also require ROO. The cost to exporters of establishing origin has been estimated at between $\$ 84$ million and $\$ 140$ million. Thus, the net gain of an FTA relative to a CU ranges from $\$ 42$ million to negative $\$ 14$ million, which averages to $\$ 14$ million or some $0.3 \%$ of GDP.

However, this does not include other important costs associated with ROO. These include the trade diversion and welfare loss typically associated with ROO-a major problem for a very small economy like WBG that needs to obtain many of its inputs from the ROW, the tendency of the ROO to become a protectionist device-with additional welfare losses, and the cost of administering the ROO. Thus, the CU with Israel is preferable to an FTA, once all the costs associated with the FTA are taken into account.

\subsection{Conclusion on NDTP, FTA or CU}

The analysis leads to the following trade policy recommendation:

The PA should pursue a non-discriminatory trade policy (NDTP) with all its neighbors, but only under the condition of an open and transparent trade policy enforced by credible lock-in mechanisms. Otherwise, a CU with Israel is likely to be preferable.

\section{Exports of Labor Services}

There are two markets for WBG unskilled labor, the domestic market in WBG and the labor market in Israel. There are essentially two sources of unskilled labor in Israel's market, Palestinian and foreign (e.g., Romanian, Thai, and other). The main if not only source of unskilled labor in WBG is Palestinian. However, low-wage Jordanian labor might be attracted to work in WBG in the final status stage, given that access to Israel's labor market has raised WBG wages. On the other hand, a high rate of WBG unemployment would have the opposite effect. In the analysis that follows, we first abstract from Jordanian labor access to the WBG labor market. 


\subsection{Benefits}

WBG would greatly benefit from a steady and stable export of labor services to Israel. Ruppert (2001) finds that, after controlling for individual factors, Palestinians earn $91 \%$ more in Israel than in WBG. Thus, the wage premium earned in Israel's labor market is a very important source of additional income for WBG workers. Net factor income from Palestinian employment in Israel has been estimated at $\$ 828$ million (Ruppert, 2001). This means that Palestinian labor would have earned \$433 million working in WBG, and earned $\$ 395$ million (or $91 \%$ ) more by working in Israel, or over $9 \%$ of GDP. Even if the wage premium were only $40 \%$, the gain from exports of labor services would be $\$ 237$ million, or close to $6 \%$ of GDP. Hence, it is paramount for WBG to maintain access to Israel's labor market, irrespective of the trade policy between Israel and WBG. ${ }^{22}$

Borders are closed at times, and even when they are not, painstaking border controls can greatly increase the cost of working in Israel or decrease the probability of being hired on a given day. It is assumed here that these issues will be mostly resolved in the final status stage and will no longer act as a constraint. However, if they are not resolved, the benefit of access to Israel's labor market must be reassessed. It is also assumed that arrangements will be made so that some of the taxes Israel collects on Palestinian labor (e.g., deductions for pensions) will be transferred to the PA or to private accounts, and that the issue of differential income taxation favoring foreign workers will be resolved.

\subsection{Losses}

Palestinians only have access to unskilled jobs in Israel, even though some of the Palestinians working in Israel are skilled (and prefer to work for high unskilled wages in Israel rather than for lower skilled wages in WBG). This has several consequences. First,

\footnotetext{
${ }^{22}$ This is mentioned because it is unclear what Israel's reaction, if any, would be to a decision by the PA to implement a non-discriminatory trade policy whereby Israel would be denied preferential access to WBG markets.
} 
the skills of skilled Palestinians working in Israel are likely to depreciate. Second, assuming there are positive externalities whereby skilled workers typically raise the productivity of unskilled ones by interacting with them in the production process (as assumed in some of the "endogenous growth" theory, e.g., Lucas 1988), then the productivity of unskilled labor in WBG is lower than if all skilled Palestinians worked in WBG. Third, given the higher unskilled wages for Palestinians due to their access to Israel's labor market, the return to skills is now lower in WBG, with a negative effect on the incentive for Palestinians to acquire education and skills.

Second, and probably more important, Palestinians working in Israel create a "Dutch-disease" type phenomenon in the economy of WBG. Ruppert (2001) reports that in 1999 “ ... nearly $23 \%$ of employed Palestinians held jobs in Israel or Israeli settlements (averaging 126,000 out of a total employment level of 555,000)." This results in fewer workers in WBG and in higher wages there. ${ }^{23}$ The high wage rate in WBG lowers the international competitiveness of the Palestinian economy, with a negative impact on the production of all tradable (exportable and import-competing) goods and services.

The negative effect on the competitiveness of tradable sectors is not considered to be a problem as long as the income from exports of labor services is permanent and reasonably stable. If it is, then the result is simply an adjustment by the economy to a change in its comparative advantage, with the new source of income financing additional imports, and with other now less competitive tradable sectors shrinking. This would seem to be the case for WBG in the final status stage as long as Israel continues to prosper and does not experience a massive economic decline, and if security problems are resolved.

The Dutch disease would in fact be a disease if the source of income were viewed as permanent but were in fact temporary (as occurred in the 1960s in the Netherlands with natural gas, and in the 1980s in Nigeria and Mexico with oil) because it would result

\footnotetext{
${ }^{23}$ Ruppert (2001) shows the relation between unskilled wages in Israel and WBG, with the WBG wage a function of the Israeli wage, the probability of getting a job, and the cost of transport, border controls etc.
} 
in excessive foreign borrowing and spending. ${ }^{24}$ The problem also arises because the reallocation of resources associated with the Dutch disease is likely to be irreversible due to high adjustment costs, resulting in permanent losses.

But even if the new source of income were permanent, it might result in dynamic costs. If manufacturing in WBG entails learning-by-doing or entails positive externalities at the industry level whereby firms benefit from other firms' presence and production (benefits which are typically not internalized by individual firms), access to Israel's labor market would reduce manufacturing output and generate dynamic losses. ${ }^{25}$ Also, a larger manufacturing sector can support a larger number of firms providing manufacturing services, thus lowering the cost of these services (especially non-tradable ones) and raising the level of competitiveness. These "economic geography" or "agglomeration" benefits are potentially quite important. Thus, by raising WBG wages, access to Israel's labor market may result in permanent productivity losses for WBG manufacturing firms.

Thus, stable and permanent access to Israel's labor market is on the whole economically beneficial for WBG, though it is likely to entail some negative dynamic effects by reducing the level of productivity. How can this be dealt with in an efficient manner?

\subsection{Palestinian Permit}

One way to reduce the effect of access to the Israeli labor market on wages and competitiveness is for the PA to institute a system of fee-based permits for labor working in Israel. This arrangement will have various effects, four of which are likely to be beneficial and one which is likely to be ambiguous. First, the arrangement will provide the PA with an important source of additional revenue, enabling it to lower taxes (e.g., tariffs and the VAT). Second, since the net wage rate obtained by working in Israel will be reduced by the work permit fee, it will reduce the incentive to work in Israel. More

\footnotetext{
${ }^{24}$ Theory and evidence have shown that consumption responds essentially to changes in permanent income, not to changes in transitory income that go essentially into savings. The Dutch disease is essentially caused by a "permanent income" reaction to a transitory income increase.

${ }^{25}$ Note that savings in situations of Dutch disease are typically invested in less or non-productive activities, including residential construction.
} 
labor will remain in WBG and this will lower the wage rate there. This will help improve the international competitiveness of industry in WBG.

Third, one might be tempted to argue that if it is beneficial to work in Israel and obtain higher wages, restricting access to Israel's labor market through the sale of feebased permits should be harmful. But this is not necessarily true. Palestinian workers seem to have a certain degree of market power in the unskilled labor market of Israel. Foreign workers from Eastern Europe and South-East Asia do compete with Palestinians in the Israeli unskilled labor market. If the supply of foreign workers were infinitely elastic (at the wage rate they obtain at home plus both the cost of coming to Israel and living there rather than at home), than Palestinian workers would have no market power. However, Palestinian and foreign workers are not perfect substitutes.

For one, many Palestinians know some Hebrew, typically have more experience, and know more about the Israeli labor market than foreign workers do. Farsakh (1999, p. 19) finds that Palestinian and overseas workers are not perfect substitutes because their expertise differs, they work in different parts of Israel, and Palestinians are more experienced. Amir (1999) provides a detailed description of the differences between Palestinian and foreign labor. Second, the Israeli government restricts the inflow of foreign labor--though not always very effectively--so that their supply is not infinitely elastic.

Thus, WBG labor does seem to have market power in the Israeli labor market. This would imply an optimal export tax on labor services, whereby the PA would impose a tax on labor working in Israel. This would result in fewer Palestinians going to work in Israel and in higher unskilled wages there. Thus, assuming that WBG labor has market power in Israel's unskilled labor market, WBG authorities are able to shift part of the tax to Israeli employers. Such an export tax can be implemented with a system of fee-based permits to work in Israel. If the fee is equivalent to the optimal export tax, then welfare of the WBG will be higher than in the absence of these permits. Even if WBG labor has little or no market power in the Israeli labor market, a fee-based permit system is likely to generate 
dynamic gains because WBG is likely to benefit from increased competitiveness and dynamic externalities.

Fourth, even though the Israeli and WBG governments may fully cooperate in a final status stage, there may still be security threats from groups or individuals. The WBG authorities could use the requirement of a permit to work in Israel as a screening device. This would help the Israeli border police deal with security controls and would reduce the transaction costs of crossing into Israel.

Four sources of benefits, associated with the WBG policy of requiring a fee-based permit to work in Israel, have been identified. On the other hand, the outcome for the Palestinian workers is ambiguous. They experience a direct loss from earning a lower wage in WBG (and also in Israel after paying for the permit). However, they are likely to experience an indirect benefit. Given the added tax revenue, workers could benefit either from lower taxes or from better and/or more services, especially if the services are targeted towards them. Since welfare of WBG as a whole would presumably be higher with the fee-based permits (as long as the fee is close to the optimal tax), workers could be fully compensated without anyone else in WBG losing. The losers from this policy would be the Israeli employers who would now have to pay a higher wage rate to a smaller number of Palestinian workers. Whether workers win or lose very much depends on the quality of governance in WBG. The assumption made so far is that one dollar (or NIS or JD) in private hands is equivalent to one dollar in the hands of the authorities. This assumption may be reasonable for some countries, though not necessarily for others where the public sector is either ineffective or captive of private interest groups or both.

To provide some order of magnitude, and as stated before, total net factor income from Palestinian employment in Israel amounts to \$828 million, and Ruppert (2001) estimates Palestinian wage rates in Israel to be $91 \%$ higher than in WBG. In other words, Palestinians receive a $91 \%$ premium from working in Israel (and would have earned a total of $\$ 434$ million working in WBG). Hence, charging a $10 \%$ fee (relative to the wage rate in WBG) would not be unreasonable and would amount to $\$ 43$ million. In fact, lower transactions costs in the final status stage might result in an increased supply of 
Palestinian labor willing to work in Israel and thus in a larger revenue from the fee, especially if the reduction in transactions costs is larger than the fee.

Ruppert (2001) has estimated these transactions cost and finds that they are about $37 \%$ of daily income. Since the wage rate in Israel is $91 \%$ higher than in WBG, transactions costs are $70 \%$ of the WBG wage rate (37\% of $191 \%)$. Assume that transactions costs on Palestinian labor fall by 50 percentage points to $20 \%$ of the WBG wage rate in the final status stage, and that the fee charged is equal to $50 \%$ of the WBG wage rate (or $26 \%$ of the Israeli wage rate). Then, the net benefit of working in Israel would be unchanged, and there would be no impact on the supply or wage rate of Palestinian labor working in Israel. And the revenues from the permit fee would amount to $\$ 217$ million, or over $5 \%$ of GDP.

One problem is the porosity of the border between Israel and the West Bank. Israeli employers prefer to hire workers who have no Israeli permit because they are cheaper. Thus, in order for the Palestinian permit system to work, the border will have to be carefully monitored for labor movements, and this will require border controls. These would be available under an FTA or a NDTP policy but not under a CU. Thus, assuming a system of fee-based permits were put into place, the existence of border controls would be an additional reason for which a NDTP would be preferable to a CU.

However, even with a NDTP, it is likely that there will be some leakage, with part of the Palestinian labor force working in Israel trying to avoid paying the fee. When determining the level of the fee, the PA should take into account that the degree of leakage may rise with the level of the fee. Such a situation would imply a lower optimal fee.

\subsection{Jordanian labor}

What about Jordanian labor? In the final status stage, and given the higher wages in the West Bank than in Jordan, there is no reason to believe that workers from Jordan will not want to work there. The PA should allow this development to take place because WBG as a whole will gain. Jordan and Israel will also benefit as a whole. Jordan will 
gain from exporting labor services to the West Bank at higher wages (which is equivalent to an improvement in Jordan's terms of trade). Jordanian labor will benefit from access to higher wages, Jordanian workers in Jordan will equally benefit, and employers in Jordan will lose. The West Bank will benefit from importing cheaper labor services (also an improvement in its terms of trade), and from the fact that lower wages will raise the competitiveness of its industry. ${ }^{26}$ Palestinian labor in WBG will lose.

The lower wage rates in the West Bank will raise the supply of labor willing to work in Israel. This will provide WBG authorities with an increase in revenue from the fee charged on permits to work in Israel and will dampen the decline in wage rates in WBG. And despite the fact that the increase in the number of Palestinians working in Israel lowers the wage rate they can earn there and hurts Palestinian workers already employed in Israel, it can be shown that WBG will increase its gain from Palestinians working in Israel as long as the optimal fee on work permits is charged by the PA. Israel as a whole will benefit from cheaper imports of Palestinian labor services (terms of trade gain), though Israeli and foreign unskilled labor will lose.

An important question in this context is whether the West Bank will allow entry by Jordanian workers. When Israel created a "safe passage" in late 1999 between Gaza and the West Bank, workers from Gaza went to work in the West Bank where wages are much higher. This resulted in demonstrations by West Bank workers who were unwilling to be accept competition from workers from Gaza. The same might occur with Jordanian labor, though the degree to which WBG will open its labor market to Jordanian workers will also depend on the unemployment rate in the West Bank. Moreover, a number of Jordanian Palestinians are originally from the West Bank and may decide to return once the final status stage is reached.

\subsection{Conclusion on Labor Services}

The analysis leads to the following labor market policy recommendation:

\footnotetext{
${ }^{26}$ For this to be a benefit, one must assume some form of positive externalities, such as productivity effects that are external to the firm but internal to the industry or to the industrial sector as a whole (e.g., if firm productivity depends positively on industry output or agglomeration externalities).
} 
The PA should establish a system of fee-based permits for Palestinian workers working in Israel, and it should consider allowing access by Jordanian workers to the WBG labor market.

\section{Currency}

The issue of currency choice is only briefly examined here. A more detailed analysis is found in Kleiman (1999), though the proposals considered differ somewhat. Currency is one of the basic symbols of national sovereignty. It can provide economic benefits but it carries important risks. One risk is that a government would make use of the printing press to finance fiscal deficits caused by pressures for additional spending from a variety of interest groups, thus resulting in inflation.

The WBG uses the NIS for most transactions. The seigniorage on that accrues to Israel. This is a loss for WBG which has been estimated by EC (1999) at $\$ 50$ million or $1 \%$ of GNP (calculated at the interest rate on Israeli government bonds). One possibility is for Israel to compensate WBG for this loss. On the other hand, as argued by Depres et al. (1966) for the US dollar, Israel could argue that WBG benefits from Israel's monetary policy and the stability of the NIS and that this facilitates domestic transactions as well as trade and other transactions with Israel, its main trading partner.

On the other hand, and for obvious reasons, it is likely to be politically unfeasible to use the NIS in WBG in the long run. An alternative is to replace it with a major currency, such as the US dollar, which is already used by Palestinians as a reserve currency. Precedents of countries that have adopted the US dollar as their currency include Ecuador and El Salvador, and Argentina has established a Currency Board whereby its currency is fixed to the US dollar on a one-to-one basis and it cannot resort to the inflation tax. Another alternative is the euro. The euro will replace most EU currencies on January 1, 2002. If it performs satisfactorily (with respect to the dollar), and given that the EU is the largest trading partner of WBG after Israel, the euro might have to be considered as another alternative. 
An intermediate solution (between the choice of NIS and a major currency), though possibly not altogether satisfactory to the Palestinians, is to use the NIS but with different symbols on the notes. This solution has been applied by the United Kingdom in the case of Scotland where the British Pound circulates but with Scottish rather than English symbols. $^{27}$

\section{Concluding Comments}

This paper has examined various options regarding the trade policy of WBG in the final status stage and policies related to the WBG export of labor services to Israel. It concludes that a non-discriminatory trade policy is likely to be superior to a $\mathrm{CU}$ with Israel, and the CU is likely to be superior to an FTA with Israel. But there is an important caveat. Replacing the CU with a non-discriminatory trade policy must entail an open, liberal trade regime with low, uniform tariffs bound at the WTO at the applied rates, and the implementation of a credible mechanism to constrain the use of protectionist nontariff measures. The paper also recommends that WBG pursue an open nondiscriminatory trade policy with respect to Jordan.

With respect to the labor market, the paper recommends that the PA establish a system of fee-based permits for Palestinian labor working in Israel and that it consider providing Jordanian workers access to the WBG labor market.

More generally, a newly independent Palestinian state has the choice of becoming an open, market-oriented, competitive and dynamic economy, with a government enforcing simple, transparent and uniform rules that apply to all. This will enable the entire population to share the fruits of economic growth. The alternative of a government subject to successful rent-seeking activities and providing special favors to various interest groups is likely to result in economic stagnation, with negative consequences for the stability and the well-being of WBG and the region as a whole.

${ }^{27}$ Thanks are due to Peter Robson for providing this information. 


\section{References}

Shmuel Amir. 1999. "The Demand of Palestinian Workers in Israel-Counterfactual and Prospects." Chapter 3 in Economic Community. Evaluating the Paris Protocol. Economic Relations between Israel and the Palestinian Territories. Brussels (July).

Claus Astrup and Sebastien Dessus. 2001. "Trade Options for the Palestinian Economy: Some Orders of Magnitude." Middle East and North Africa-Region, World Bank (February), Washington, D.C.

Economic Community. 1999. Evaluating the Paris Protocol. Economic Relations between Israel and the Palestinian Territories. Brussels (July).

Yousef S. Daoud. 2000. "Revenue and Direct Cost Implications of a Policy Switch to an FTA." Paper prepared for PECDAR (September).

E. Depres, C. Kindleberger, and W.S. Salant. 1966. "The Dollar and World Liquidity. A Minority View." The Economist (February 5).

Leila Farsakh. 1999. "Palestinian Labor Flows to Israel and the Economic Protocol: A Critical Assessment." Chapter 2 in Economic Community, op. cit.

Stanley Fischer, Leonard J. Hausman, Anna D. Karasik and Thomas C. Schelling (eds.). 1994. Securing Peace in the Middle East. MIT Press: Cambridge and London.

J. Herin. 1986. "Rules of Origin and Differences between Tariff Levels in EFTA and in the EC." EFTA Occasional Paper No. 13. Geneva (February).

Veronique Kessler. 1999. "Palestine's External Trade Performance Under the Paris Protocol: Hopes and Disillusions." Chapter 5 in European Commission, op. cit.

Anne O. Krueger. 1997. "Free trade agreements versus customs unions." Journal of Development Economics 54: 169-187.

Bartolomiej Kaminski and Manuel de la Rocha. 2001. "EU Stability and Association Framework: Implications for Trade Policies." Mimeo, DECRG, World Bank.

Ephraim Kleiman. 1999. "Evaluating the Fiscal and Monetary Arrangements of the Paris Protocol-A Counterfactual Analysis." Chapter 7 in European Commission, op. cit.

Robert E. Lucas. 1988. "On the Mechanics of Economic Development." Journal of Monetary Economics.

Arvind Panagariya and Ishak Diwan. 1997. "Trade Policy Options for the West Bank and Gaza Strip". Palestine Economic Policy Research Institute (MAS) Discussion Paper, Jerusalem, and World Bank, Washington, D.C. (January). 
Kishore Rao. 2000. "Free Zones in the Middle East: Development Patterns and Future Potential," Chapter 11 in B. Hoekman and H. Kheir-El-Din (eds.) Trade Policy Developments in the Middle East and North Africa. World Bank. Washington, D.C.

Elizabeth Ruppert Bulmer. 2001. "Distortions in the Palestinian Labor Market and Implications for Employment Growth." Mimeo, MNSED, World Bank. Washington, D.C. (April).

Athanasios Vamvakidis. 1998. "Regional Integration and Economic Growth." World Bank Economic Review 12 (2): 251 - 270.

World Bank. 2000. Trade Blocs. A Policy Research Report. Washington, D.C.

WTO. 1999. Trade Policy Review. Israel. Geneva. 
Table 1. WBG Loss of CU and FTA as Compared to NDTP," and of Access to Israel's Labor Market (in \$ million)

1.0 Customs Union (CU)

$1.1 \quad$ Losses

1.1.1 Indirect Imports

- Loss of tariff and purchase tax revenues 133

- Excess leakage of VAT revenues

Total

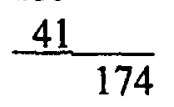

1.1.2 Transfers

- No Smuggling: Loss 200

\begin{tabular}{ll} 
Gain & 64 \\
\hline Net $\quad 136$
\end{tabular}

- Smuggling: Loss 160

$\begin{array}{ll}\text { Gain } & 64 \\ \text { Net } \quad 96\end{array}$

- Total Losses: $\quad$ No Smuggling 310

$1.2 \quad$ Gains

Border Costs Savings $\quad 48$

1.3 Net Loss

No Smuggling $\quad 262$

Smuggling $\quad 222$

$2.0 \quad$ FTA

$2.1 \quad$ Losses

2.1.1 Transfers

- No Smuggling: 136

- Smuggling:

2.1.2 Rules of Origin

- Cost to exporters $=3-5 \%$

of import value from all

FTA partners: $\quad 84$ to 140

- Other costs (trade diversion, and other): $\chi$ (not quantifiable)
2.1.3 Total Losses:
$(180+\chi)$ to $(276+\chi)$

\subsection{Access to Israel's Labor Market}

Benefit:

395

\footnotetext{
- NDTP=non-discriminatory trade policy with tariffs at present MFN rates. Gains of NDTP would be larger if trade policy were further liberalized, though the risk with a NDTP is that it may turn protectionist and be worse than a CU.
} 


\section{Appendix}

\section{West Bank-Gaza Imports of Services from Israel $(\$ 000,1998) *$}

Total Tradable

$\begin{array}{ll}\text { P-E } & \text { Electricity, gas, water supply } \\ \text { P-F } & \text { Construction } \\ \text { P-G.5020 } & \text { Maintenance and repair of motor vehicles } \\ \text { P-G.5050 } & \text { Retail sale of automotive fuel } \\ \text { P-G.50R } & \text { Sale of motor vehicles and parts } \\ \text { P-G.51 } & \text { Wholesale } \\ \text { P-G.5260 } & \text { Repair of personal and household goods } \\ \text { P-G.52R } & \text { Other retail sale } \\ \text { P-H } & \text { Hotels, restaurants } \\ \text { P-I } & \text { Transport, storage, communications } \\ \text { P-I.6411 } & \text { National post activities } \\ \text { P-I.64R } & \text { Remaining communication } \\ \text { P-J.6511 } & \text { Central banking } \\ \text { P-J.6519 } & \text { Other monetary intermediation } \\ \text { P-J.660 } & \text { Insurance, pension funding, except compulsory social security } \\ \text { P-J.R } & \text { Other fin. interm., auxiliary activities } \\ \text { P-K } & \text { Real estate, renting, business activities } \\ \text { P-L } & \text { Public administration, defence; compulsory social security } \\ \text { P-M } & \text { Education } \\ \text { P-N } & \text { Health, social work } \\ \text { P-O } & \text { Other community, social, personal service activities } \\ \text { P-P } & \text { Private households with employed persons } \\ & \\ & \text { Total } \\ & \text { * The calculation of tradables assumes that half of } \\ & \text { categories P-H, P-I and P-I.64R consist of tradables. } \\ & \end{array}$

$\begin{array}{rr}138604 & 0 \\ 0 & 0 \\ 296 & 0 \\ 0 & 0 \\ 0 & 0 \\ 0 & 0 \\ 2362 & 0 \\ 0 & 0 \\ 61548 & 30774 \\ 88159 & 44080 \\ 1069 & 0 \\ 45399 & 22700 \\ 0 & 0 \\ 46 & 0 \\ 12017 & 0 \\ 0 & 0 \\ 69436 & 0 \\ 28924 & 0 \\ 7867 & 0 \\ 31518 & 0 \\ 4490 & 0 \\ 0 & 0 \\ 491,734 & 97554\end{array}$


Title

WPS2806 Dirty Exports and Environmental Regulation: Do Standards Matter to Trade?

WPS 2807 The Role of Natural Resources in Fundamental Tax Reform in the Russian Federation

WPS2808 A Capital Accord for Emerging Economies

WPS2809 On the Measurement and Impact of Fiscal Decentralization

WPS2810 Growth, Distribution, and Poverty in Africa: Messages from the 1990s

WPS2811 The Epidemiological Impact of an HIVIAIDS Vaccine in Developing Countries

WPS2812 Can Financial Markets be Tapped to Help Poor People Cope with Weather Risks?

WPS2813 The Collective Model of the Household Kaushik Basu and an Unexpected Implication for Child Labor: Hypothesis and an Empirical Test

WPS2814 Estimating the Endogenously Determined Intrahousehold Balance of Power and Its Impact on Expenditure Pattern: Evidence from Nepal

WPS2815 Pricing Currency Risk: Facts and Puzzles from Currency Boards

WPS2816 Explaining the Migration of Stocks from Exchanges in Emerging Economies to International Centers

WPS2817 Does Sequencing Matter? Regulation Scott Wallsten and Privatization in Telecommunications Reforms

WPS2818 Corporate Governance, Investor Protection, and Performance in Emerging Markets

WPS2819 Goals for Development: History, Prospects, and Costs

Author

John S. Wilson

Tsunehiro Otsuki

Benoît Bosquet

Andrew Powell

Robert D. Ebel

Serdar Yilmaz

Luc Christiaensen

Lionel Demery

Stefano Paternostro

John Stover

Geoff P. Garnett

Steve Seitz

Steven Forsythe

Jerry Skees

Panos Varangis

Donald Larson

Paul Siegel
Ranjan Ray

Gayatri Koolwal

Ranjan Ray

March 2002

Sergio L. Schmukler Luis Servén

Stijn Claessens Daniela Klingebiel

Sergio L. Schmukler

Date

March 2002

March 2002

March 2002

March 2002

March 2002

March 2002

March 2002

March 2002

March 2002

March 2002

April 2002

Leora F. Klapper Inessa Love

Shantayanan Devarajan Margaret J. Miller Eric V. Swanson

April 2002

April 2002
Contact for paper

P. Flewitt

32724

D. Duff

39506

E. Mekhova 85984

M. Morris

37285

N. Nouviale 34514

H. Sladovich 37698

P. Kokila 33716

N. Jameson

30677

N. Jameson 30677

E. Khine 37471

E. Khine 37471

P. Sintim-Aboagye 37644

A. Yaptenco 31823

S. Brickland 30944 
Policy Research Working Paper Series

\begin{tabular}{|c|c|c|c|c|}
\hline & Title & Author & Date & $\begin{array}{l}\text { Contact } \\
\text { for paper }\end{array}$ \\
\hline WPS2820 & $\begin{array}{l}\text { The Privatization of the Russian } \\
\text { Coal Industry: Policies and Processes } \\
\text { in the Transformation of a Major } \\
\text { Industry }\end{array}$ & $\begin{array}{l}\text { Igor Artemiev } \\
\text { Michael Haney }\end{array}$ & April 2002 & $\begin{array}{l}\text { V. Joseph } \\
32155\end{array}$ \\
\hline WPS2821 & $\begin{array}{l}\text { Income, Weaith, and Socialization } \\
\text { in Argentina: Provocative Responses } \\
\text { from Individuals }\end{array}$ & Daniel Lederman & April 2002 & $\begin{array}{l}\text { P. Soto } \\
37892\end{array}$ \\
\hline WPS2822 & $\begin{array}{l}\text { An Econometric Analysis of IBRD } \\
\text { Creditworthiness }\end{array}$ & David Mckenzie & April 2002 & $\begin{array}{l}\text { C. Mendoza } \\
80599\end{array}$ \\
\hline WPS2823 & $\begin{array}{l}\text { Real Exchange Rate Uncertainty } \\
\text { and Private Investment in Developing } \\
\text { Countries }\end{array}$ & Luis Servén & April 2002 & $\begin{array}{l}\text { P. Soto } \\
37892\end{array}$ \\
\hline
\end{tabular}

